\title{
Clinical Reasoning: Young adult with dysphagia and severe weight loss
}

Obehioya Irumudomon, MD, and Partha S. Ghosh, MD

Neurology ${ }^{\circledR}$ 2018;91:e1083-e1086. doi:10.1212/WNL.0000000000006169

\section{Section 1}

A 20-year-old man presented with progressive dysphagia for 6 months to both liquids and solids with intermittent choking episodes. There was no nasal regurgitation, fatigability, or diurnal variation of dysphagia or difficulty in chewing. He had lost about 80 pounds in 6 months. He felt short of breath after walking for a short distance and climbing 2 flights of stairs and could not lie flat. He described muscle twitching in his face as well as arms and legs. He denied weakness of the upper or lower limbs, sensory symptoms, bladder or bowel problems, or uncontrollable laughing or crying. He had Lyme disease 5 years ago with left-sided facial palsy. The patient was of Hispanic ancestry and family history over 3 generations was negative for neuromuscular disorders, dementia, or prominent psychiatric disorders. On neurologic examination, he had a flat affect but normal bedside screening cognitive functions. His speech was nasal and his voice was hoarse. He had residual left lower motor neuron facial palsy. Cranial nerve V (motor and sensory) functions were normal. Palatal movements and gag reflex were normal. He had bilateral tongue atrophy, weakness, and fasciculations (video 1); perioral fasciculations were also present. There was mild lower limb spasticity and weakness in the following muscles: first dorsal interosseous (FDI) 4+/5, triceps 5-/5, deltoids $4+/ 5$, gluteus maximus 4+/5, neck flexion $4 / 5$. There was wasting of the periscapular muscles and FDI. There was no split hand phenomenon. Fasciculations were present in shoulder, biceps, thighs, and calves. Reflexes were $3+$ and symmetrical at the biceps, triceps, brachioradialis, patellae, and ankles with flexor plantar responses; increased finger flexor and crossed adductor reflexes were present. Jaw jerk and snout reflexes were absent. Sensory and cerebellar examination results were normal.

\section{Question for consideration:}

1. What is the localization and differential diagnosis for the patient's presentation?
Correspondence

Dr. Ghosh

partha.ghosh@

childrens.harvard.edu

\section{MORE ONLINE}

๑ Video

\section{GO TO SECTION 2}

From the Department of Neurology (O.I.), Lahey Clinic, Burlington; and Department of Neurology (O.I., P.S.G.), Boston Children's Hospital, MA.

Go to Neurology.org/N for full disclosures. Funding information and disclosures deemed relevant by the authors, if any, are provided at the end of the article. 


\section{Section 2}

The patient presented with progressive bulbar palsy. Neurologic causes of dysphagia can be due to central or peripheral nervous system disorders. ${ }^{1}$ Central causes include stroke (chronic course made it unlikely), brainstem tumors, neurodegenerative disorders (leukodystrophies [e.g., adult-onset Alexander disease]), mitochondrial disorders (e.g., mitochondrial myopathy, encephalopathy, lactic acidosis, and stroke-like episodes causing brainstem stroke), and structural lesions at the cranio-cervical junction (progressive course and upper motor neuron signs might suggest the latter 3 causes). CNS infections (bacterial/viral/fungal) need to be ruled out. Neuromuscular causes include motor neuron disorders, neuropathies, neuromuscular junction disorders, and myopathies. Among the motor neuron disorders, amyotrophic lateral sclerosis (ALS) was high on the differential as our patient had a progressive course and both upper and lower motor neuron signs without sensory symptoms. Riboflavin transporter deficiency neuronopathy (Brown-Vialetto-Van Laere [BVVL] syndrome) can present with bulbar palsy. ${ }^{2}$ However, deafness is a common symptom and tendon reflexes are usually depressed due to sensory neuronopathy, none of which was present in our patient. Fazio-Londe syndrome is similar to BVVL but without deafness and presents in the first decade. ${ }^{2}$ Spinobulbar muscular atrophy (Kennedy disease) is an $\mathrm{X}$-linked recessive disorder that presents with atrophy and fasciculations of the bulbar and limb muscles and gynecomastia (absent in our case). ${ }^{3}$ Typically the course is more insidious in the third to fifth decades and tendon reflexes are depressed or absent, making this less likely in our case. Adultonset spinal muscular atrophy does not present with bulbar symptoms; also hyperreflexia was against this diagnosis. Diffuse hyperreflexia made peripheral neuropathy unlikely in our case. Myasthenia gravis, particularly MuSK-positive myasthenia, could present with bulbar symptoms, tongue atrophy, and neck weakness, but hyperreflexia and fasciculations made this unlikely. Finally, various muscle disorders, genetic myopathies (myotonic dystrophy, oculopharyngeal muscular dystrophy), or inflammatory myopathies could present with dysphagia but lack of characteristic pattern of weakness, fasciculations, and hyperreflexia made myopathy unlikely.

\section{Question for consideration:}

1. What investigations can help to narrow the differential diagnosis?

GO TO SECTION 3 


\section{Section 3}

MRI brain was normal, ruling out stroke, brainstem tumor, structural lesions of the cranio-cervical junction, and some of the neurodegenerative disorders like adrenoleukodystrophy. Lumbar puncture was negative for infections (routine culture and meningitis/encephalitis PCR panel) with normal cell count and chemistry. The patient had normal blood counts, liver function tests, creatine kinase, thyroid function tests, $\mathrm{B}_{12}$, paraneoplastic panel, HIV, rapid plasma reagin, Lyme titers, copper, and hexosaminidase A (low level seen in GM2 gangliosidosis or Tay-Sachs disease, which can be ALS mimicker). ${ }^{3}$ Nerve conduction studies showed normal motor and sensory conductions in the upper and lower extremities. Sensory nerve action potentials are typically reduced or absent in BVVL syndrome and Kennedy disease due to sensory neuronopathy, making these disorders unlikely in our case. ${ }^{2,3}$ Needle EMG showed fasciculations and fibrillations in the bulbar (genioglossus and masseter), cervical, thoracic, and lumbosacral myotomes. Chronic neurogenic changes (reduced recruitment of large motor unit potentials) were present mainly in the bulbar and cervical myotomes. Modified barium swallow study showed diffusely diminished pharyngeal contraction with silent aspiration of thin liquids. Pulmonary function testing (PFT) showed reduced forced vital capacity at $37 \%$ predicted; maximal inspiratory and expiratory pressures were low. Based on exertional dyspnea, inability to lie flat and abnormal PFT suggested possible diaphragmatic involvement.

\section{Question for consideration:}

1. Based on these findings, what is the most likely diagnosis?

GO TO SECTION 4 


\section{Section 4}

The patient had clinically probable (juvenile onset) ALS per El Escorial criteria: definite lower motor neuron (LMN) signs (tongue atrophy, fasciculations) in bulbar region, upper motor neuron (UMN) (hyperreflexia) and LMN signs (atrophy, fasciculations) in cervical region, and UMN (hyperreflexia, spasticity) and LMN signs (fasciculations) in lumbar and sacral regions. Next-generation sequencing panel for ALS genes (ALS2, ANG, C9orf72, CHMP2B, DCTN1, FIG4, FUS, OPTN, PFN1, SETX, SIGMAR1, SOD1, SQSTM1, TARDBP, $U B Q L N 2, V A P B, V C P$ ) did not show pathogenic mutations. He was referred to a multidisciplinary ALS clinic, counseled regarding potential gastrostomy tube placement and noninvasive ventilation, and was started on riluzole.

\section{Discussion}

ALS is a progressive neurodegenerative disorder characterized by diffuse muscle weakness and wasting. ${ }^{2}$ The average age at onset of symptoms in sporadic onset ALS is about 56 years. ${ }^{4}$ The diagnosis of juvenile ALS (JALS) should be based on the development of a clinical syndrome that meets diagnostic criteria for ALS with an age at onset less than 25 years. ${ }^{2}$ JALS is extremely rare, with an estimated prevalence of 1 in $1,000,000 .{ }^{5}$ It is sometimes challenging clinically to make an accurate diagnosis in JALS due to phenotypic variability and a broad differential diagnosis needs to be considered (discussed in Sections 2 and 3). ${ }^{2}$ Eventually all patients with JALS develop both upper and lower motor dysfunction, cognitive functions and sensory symptoms are spared, and pseudobulbar signs can be present. ${ }^{2}$

Familial ALS accounts for about 5\%-10\% of ALS cases. ${ }^{5}$ JALS is thought to be more frequently associated with genetic forms of ALS. JALS could be autosomal recessive (ALS2, SPG11, and SIGMAR1), autosomal dominant (SETX, SOD1), X-lined (UBQLN2), or due to de novo mutations (FUS). ${ }^{5-10}$ In a recent cohort of 12 patients with JALS of Chinese descent, the authors identified 5 likely pathogenic mutations (1 TARDBP and 4 FUS), 2 in familial probands and 3 in sporadic patients. ${ }^{5}$ Unlike previously reported patients with FUS mutations, who had rapid disease progression and early death, this study found a wider range of survival (mean 58.2 months). ${ }^{5}$

JALS, though rare, should be considered in the appropriate clinical context in a patient with dysphagia. A thorough neurologic examination may detect UMN and LMN signs in clinically asymptomatic areas and will help in early diagnosis and appropriate management.

\section{Author contributions}

Dr. Ghosh: study concept and design. Dr. Irumudomon: acquisition of data. Drs. Irumudomon and Ghosh: analysis and interpretation. Dr. Ghosh: critical revision of the manuscript for important intellectual content. Dr. Ghosh: study supervision.

\section{Study funding}

No targeted funding reported.

\section{Disclosure}

O. Irumudomon reports no disclosures relevant to the manuscript. P. Ghosh received consulting fees from CVS Caremark and Catalyst Pharmaceuticals. Go to Neurology.org/N for full disclosures.

\section{References}

1. Brazis PW, Masdeu JC, Biller J, eds. Localization in Clinical Neurology, 6th ed. Philadelphia: Lippincott Williams \& Wilkins; 2011.

2. Bosch AM, Stroek K, Abeling NG, et al. The Brown-Vialetto-Van Laere and Fazio Londe syndrome revisited: natural history, genetics, treatment and future perspectives. Orphanet J Rare Dis 2012;7:83.

3. Orban P, Devon RS, Hayden MR, Leavitt BR. Chapter 15: Juvenile amyotrophic lateral sclerosis. Handb Clin Neurol 2007;82:301-312.

4. Camu W, Khoris J, Moulard B, et al. Genetics of familial ALS and consequences for diagnosis: French ALS Research Group. J Neurol Sci 1999;165(suppl 1):S21-S26.

5. Liu ZJ, Lin HX, Liu GL, et al. The investigation of genetic and clinical features in Chinese patients with juvenile amyotrophic lateral sclerosis. Clin Genet 2017;92: 267-273.

6. Hentati A, Ouahchi K, Pericak-Vance MA, et al. Linkage of a commoner form of recessive amyotrophic lateral sclerosis to chromosome 15q15-q22 markers. Neurogenetics 1998;2:55-60.

7. Al-Saif A, Al-Mohanna F, Bohlega S. A mutation in sigma-1 receptor causes juvenile amyotrophic lateral sclerosis. Ann Neurol 2011;70:913-919.

8. Hayward C, Brock DJ, Minns RA, Swingler RJ. Homozygosity for Asn86Ser mutation in the CuZn-superoxide dismutase gene produces a severe clinical phenotype in a juvenile onset case of familial amyotrophic lateral sclerosis. J Med Genet 1998;35: 174.

9. Deng HX, Chen W, Hong ST, et al. Mutations in UBQLN2 cause dominant X-linked juvenile and adult-onset ALS and ALS/dementia. Nature 2011;477:211-215.

10. Baumer D, Hilton D, Paine SM, et al. Juvenile ALS with basophilic inclusions is a FUS proteinopathy with FUS mutations. Neurology 2010;75:611-618. 


\section{Neurology}

\section{Clinical Reasoning: Young adult with dysphagia and severe weight loss Obehioya Irumudomon and Partha S. Ghosh \\ Neurology 2018;91;e1083-e1086 \\ DOI 10.1212/WNL.0000000000006169}

This information is current as of September 10, 2018

\section{Updated Information \& Services}

References

Subspecialty Collections

Permissions \& Licensing

Reprints including high resolution figures, can be found at: http://n.neurology.org/content/91/11/e1083.full

This article cites 9 articles, 2 of which you can access for free at: http://n.neurology.org/content/91/11/e1083.full\#ref-list-1

This article, along with others on similar topics, appears in the following collection(s):

All Clinical Neurology

http://n.neurology.org/cgi/collection/all_clinical_neurology All Neuromuscular Disease

http://n.neurology.org/cgi/collection/all_neuromuscular_disease Amyotrophic lateral sclerosis

http://n.neurology.org/cgi/collection/amyotrophic_lateral_sclerosis_

Information about reproducing this article in parts (figures,tables) or in its entirety can be found online at:

http://www.neurology.org/about/about_the_journal\#permissions

Information about ordering reprints can be found online:

http://n.neurology.org/subscribers/advertise

Neurology ${ }^{\circledR}$ is the official journal of the American Academy of Neurology. Published continuously since 1951, it is now a weekly with 48 issues per year. Copyright (O) 2018 American Academy of Neurology. All rights reserved. Print ISSN: 0028-3878. Online ISSN: 1526-632X.

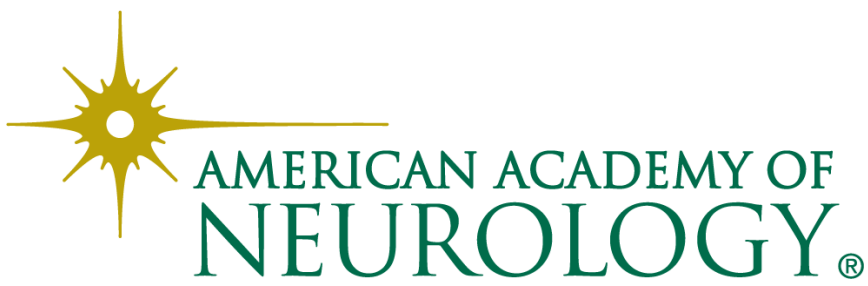

